\title{
Circular polarization reconfigurable antenna for mid-band 5G applications with a new reconfigurable technique
}

\author{
Alaa Imran Al-Muttairi, Malik Jasim Farhan \\ Department of Electrical Engineering, College of Engineering Mustansiriyah University, Iraq
}

\begin{tabular}{l}
\hline \hline Article Info \\
\hline Article history: \\
Received Nov 26, 2019 \\
Revised Jan 24, 2020 \\
Accepted Feb 8, 2020 \\
\hline
\end{tabular}

\section{Keywords:}

$5 \mathrm{G}$

Polarization reconfigurable

Polygon U-slot

Switchable slots

\begin{abstract}
In this paper, a novel low cost, single-feed, and circular polarization reconfigurable antenna is designed and fabricated for future mid-band 5G applications. An innovative technique is used in this approach, which combines three techniques, namely: polygon U-slot, switchable vertical or horizontal slots, and shorting posts. The proposed antenna can alter its polarization sense between RHCP and LHCP with the ability to adjust the axial ratio position with respect to frequency along the impedance bandwidth of the antenna. The antenna is built on RT/duroid 5880 substrate with a maximum size of $(31 * 31 * 3.15)(\mathrm{mm})^{3}$.Two real diodes are integrated across the slot to change polarization sense. CST commercial software is used to simulate the antenna, and then it is fabricated and measured practically. Good agreements between the two results are achieved. However, The antenna has impedance bandwidth starting from $3.4995 \mathrm{GHz}$ to $3.73 \mathrm{GHz}$ with overlapped axial ratio bandwidth of $2.1 \%$ for both operation senses. Also, the antenna has good gain, and it has one resonant frequency at $3.6 \mathrm{GHz}$ for both operating states.
\end{abstract}

Copyright $(5) 2020$ Institute of Advanced Engineering and Science. All rights reserved.

\section{Corresponding Author:}

Alaa Imran Al-Muttairi, Department of Electrical Engineering,

College of Engineering Mustansiriyah University, Bagdad, Iraq.

Email: al_al_44@yahoo.com

\section{INTRODUCTION}

Polarization reconfigurable antenna (PRA) is a multifunction antenna which has the ability to modify its polarization states at different time by using switches [1, 2]. In this type, the reconfigurability can be done among horizontal polarization (HP), vertical polarization (VP), polarization with a specific angle, left-hand circular polarization (LHCP), and right-hand circular polarization (RHCP) [3, 4]. Among all these types, Circular Polarization (CP) reconfigurable antennas have been received much attention due to many interesting advantages. In fact, it eliminates alignment problems related to antennas working in linear polarization, reduce the multipath effect, enhance channel capacity, increase link quality, protect from interfering signal, realize frequency reuse, and reduce co-channel interference [5-8]. Some applications of using these types of antennas are described in [9].

Based on slot etching, many polarization reconfigurable antennas are proposed in the literature. In [10], two switchable slots vertical and horizontal are used to produce CP diversity. Unfortunately, the author used an ideal switch in measurement, and a small CP bandwidth is obtained. In [5], a rectangular patch antenna with a vertical U-slot is proposed. Depend upon the length of slot arms, three polarization states are achieved. However, good CP performance is obtained. In [7], CP reconfigurable antenna for 5G application is designed and fabricated. Based on the semicircular slot with two diodes, polarization's sense can be change between RHCP and LHCP. In fact, the proposed antenna was relatively large in size, and it gives good $\mathrm{CP}$ performance in $3.4 \mathrm{GHz}$, while $3.6 \mathrm{GHz}$ is the preferred resonant frequency for the fifth generation, according to FCC. In [11], two diodes are used to configure circular ring-shaped antenna to one 
mode among LP, LHCP, and RHCP. The idea is new, and good results were obtained. However, the proposed antenna is relatively big, and it consists of a complicated biasing network. In [12], the authors proposed a circular patch with a $\mathrm{C}$-shape slot. The design depended upon air-gap to increase axial ratio bandwidth (ARBW). According to results analysis, the designed antenna exhibit narrow axial beam-width, and it occupied a big size. In [13], extended U-slot with two PIN diodes is used to designed polarization reconfigurable antenna working at different bands. The designed antenna covers a wide range of applications, but, unfortunately, it has a complicated biasing network and narrow Axial Ratio (AR) half beam angles. More polarization reconfigurable antenna designed for 5G applications are reported in [14-19].

To the best of the author's knowledge in the $5 \mathrm{G}$ antenna filed, most researches focused on designing reconfigurable antenna in mm-wave bands. Actually, middle bands, like $3.6 \mathrm{GHz}$, will be the most important frequencies in an urban area when 5G technology is deployed. So that, in this paper, a novel single feed, compact in size, and $\mathrm{CP}$ reconfigurable rectangular square patch antenna is proposed for future 5G antenna. By using switchable arms polygon U-slot, two shorting posts, and two PIN diodes, the designed antenna has the ability to alter its polarization sense between RHCP and LHCP at the $3.6 \mathrm{GHz}$ resonance frequency. As it clear from simulation and measured results, the antenna exhibits good $\mathrm{CP}$ performances with the simple biasing circuit.

\section{ANTENNA STRUCTURE AND PRINCIPLE OF OPERATION}

The geometry and the optimized dimensions of the designed antenna are shown in Figure 1 and Table 1, respectively. A square patch with a length of ( $L p)$ is printed on a square substrate with a length of (Ls). RT/duroid 5880 substrate with $\mathrm{h}=2 * 1.575 \mathrm{~mm}, \varepsilon_{r}=2.2$, and $\tan \delta=0.0004$ is used in this design. The patch length (Lp) is initially calculated from the well know formal $\left(\lambda_{g} / 2\right)$ at resonant frequency 3.6 $\mathrm{GHz}$. A coaxial feed is located at a distance $(4.6 \mathrm{~mm})$ away from the patch's center on the diagonal line. Then polygon U-slot, with identical arms, is etched with an overall length and width of $\left(0.25 \lambda_{o}\right) \mathrm{mm}$ and (0.7) $\mathrm{mm}$, respectively. Another thin slot of $(0.25) \mathrm{mm}$ wide is etched on the top region of the U-slot to provide DC isolation. To change polarization sense, two diodes (D1 and D2) are integrated across the arms of the polygon U-slot at specific and symmetric positions with similar polarity directions. Furthermore, two shorting posts are inserted at a distance $(6.9 \mathrm{~mm})$ from the feed point. These posts are using to control the axial ratio bandwidth, location of best $\mathrm{AR}$, and they contribute in bias network.

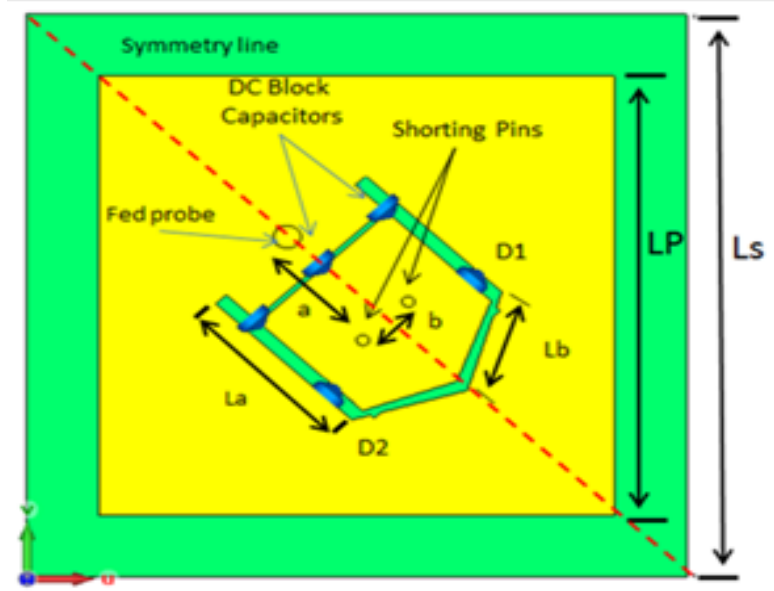

(a)

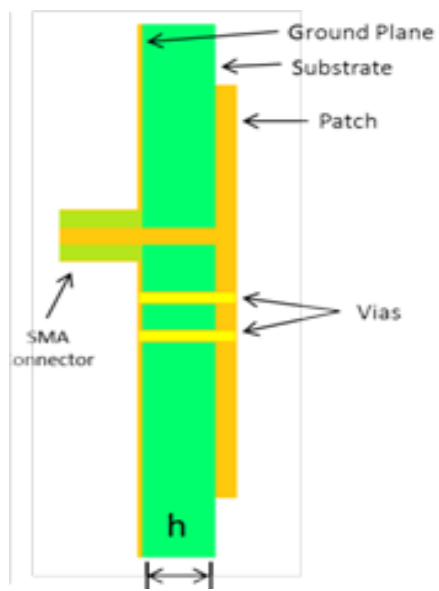

(b)

Figure 1. The proposed CP reconfigurable antenna geometry, (a) Top view, (b) Side view

Table 1. Optimized antenna dimensions

\begin{tabular}{cccccccc}
\hline Dimension & LS & LP & Lb & La & a & b & h \\
\hline Value $(\mathrm{mm})$ & 31 & 24 & 5.5 & 9 & 6.9 & 1.5 & 3.15 \\
\hline
\end{tabular}

Two beam-lead diodes (DSM8100-000) from skyworks electronics are used in antenna simulation. Each diode is modeled as RLC circuit in order to obtain acceptable agreement between simulation and measured results [20]. On the other hand, the biasing circuit consists of three DC block capacitors 
(each one has $1 \mu \mathrm{F}$ ) and one Tee biasing device. The capacitors are integrated across the thin slot to provide DC isolation and to maintain RF signal continuity over the entire patch. Whereas, a bias-Tee is used to supply the required D.C control voltage from the coaxial feed. So that, it reduces biasing circuit complexity by removing RF chocks and wires.

Due to this geometry, a voltage difference exists between the ground plane (or patch's segment surrounded by U-slot) and the remaining patch at any time. That is, if the patch voltage is connected to DC ground $(0 \mathrm{~V})$ and the segment is connected to positive voltage $(\mathrm{Vcc})$, then $\mathrm{D} 1$ is $\mathrm{ON}$ and D2 is OFF. Otherwise, If the patch voltage is positive ( $\mathrm{Vcc})$ and the segment is connected to DC ground (0V), then D1 is OFF and D2 is ON.in this design, only these operation states are considered.

However, the two diodes divided the polygon U-slot into two identical and orthogonal (vertical and horizontal) slots as shown in Figure 2. When diode 1 is ON and diode 2 is OFF, the horizontal slot is activated. In this case, the electrical length of TM01 mode in Y-direction is longer than the electrical length of TM10 mode in X-direction so that the resonant frequency related to TM01 mode is shifted to a lower value than the resonant frequency of TM10 mode. As a result, LHCP is obtained. On the other hand, when diode states are reversed, the vertical slot is activated which makes the electrical length of TM10 mode in X-direction is longer than the electrical length of TM01 mode in Y-direction. So that, the resonant frequency related to TM10 becomes lower than the resonant frequency of TM01 mode and RHCP is obtained in this case [21-23]. To approve the above principle, Figure 3 views a captured of the animated CP field for different phase values using CST. In this figure, wave propagation has been assumed to be along (+Z) direction.

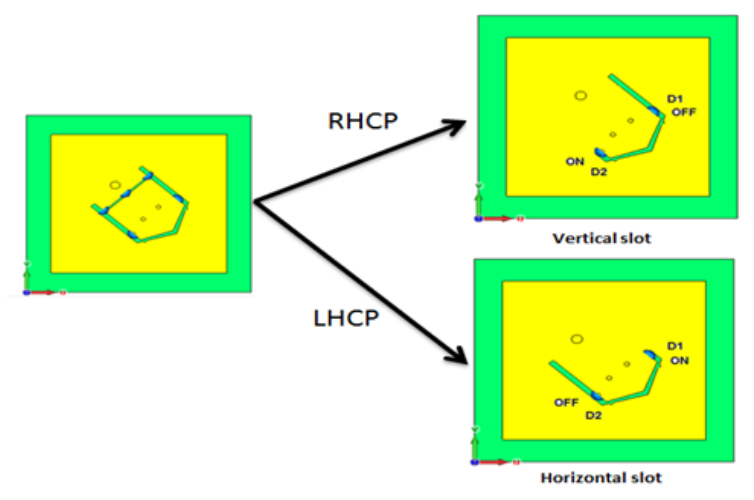

Figure 2. Designed antenna principle of operation
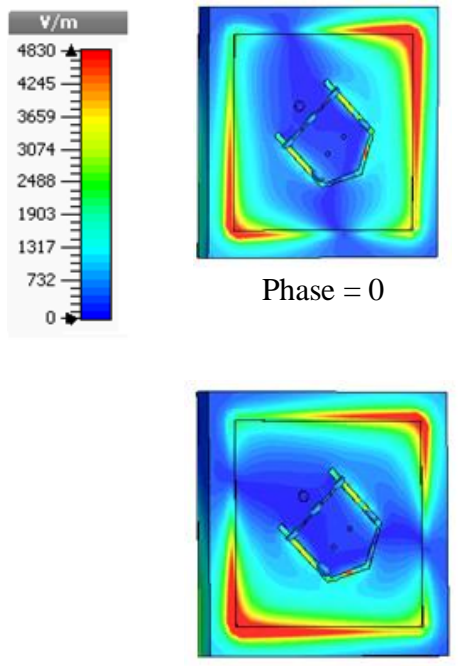

Phase $=0$

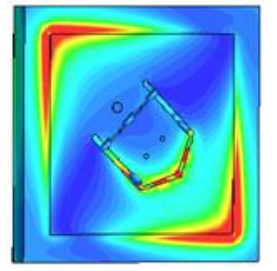

Phase $=60$

(a)

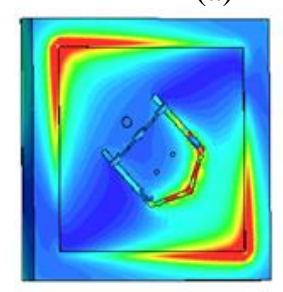

Phase $=60$

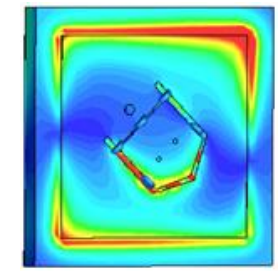

Phase $=120$

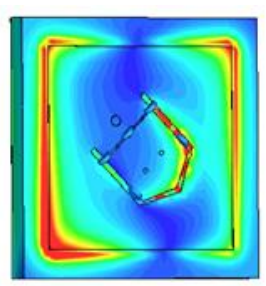

Phase $=120$

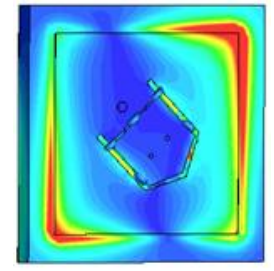

Phase $=180$

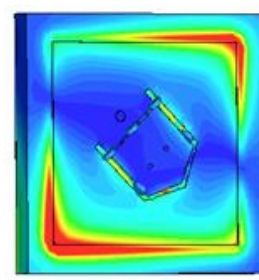

Phase $=180$

(b)

Figure 3. Graphic capture for the generated E field in, (a) Left-hand circular polarization (CW) (D1=ON \& D2=OFF), (b) Right-hand circular polarization $(\mathrm{CCW})(\mathrm{D} 1=\mathrm{OFF} \& \mathrm{D} 2=\mathrm{ON})$ 
The effect of shorting posts location on the axial ratio (AR) has been investigated [24]. As shown in Figure 4(a), the relationship between distance (a) and the AR is fitted to an empirical polynomial (1). It is clear that the $\mathrm{CP}$ is highly dependent upon the value of distance (a) in such a way that a small change leads to make antenna working at different axial ratios and hence change the polarization quality. While changing distance (b) effects on the frequency at which best AR is obtained, as shown in Figure 4(b). The relation between the value of distance (b) and frequency is described by the empirical (2).

$$
\begin{aligned}
& \mathrm{AR}(\mathrm{dB})=0.1194 \mathrm{a}^{4}-2.6488 \mathrm{a}^{3}+21.949 \mathrm{a}^{2}-81.881 \mathrm{a}+119.77 \\
& f_{\text {best AR }}(\mathrm{GHz})=0.0149 \mathrm{~b}^{3}-0.0341 \mathrm{~b}^{2}+0.0427 \mathrm{~b}+3.5497
\end{aligned}
$$

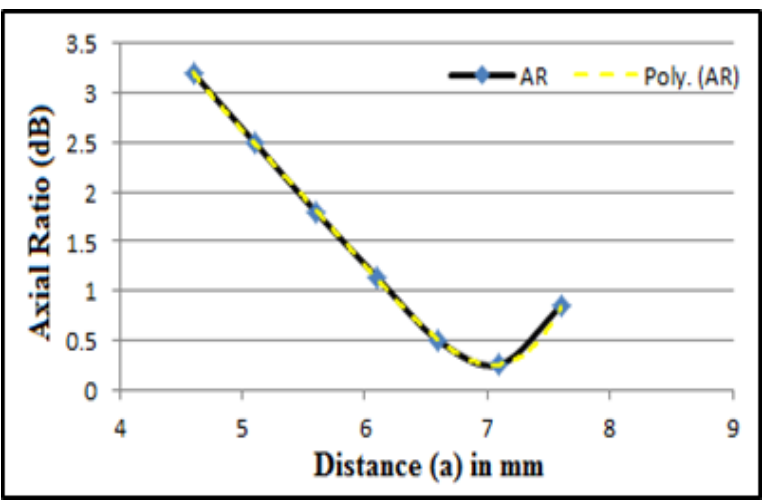

(a)

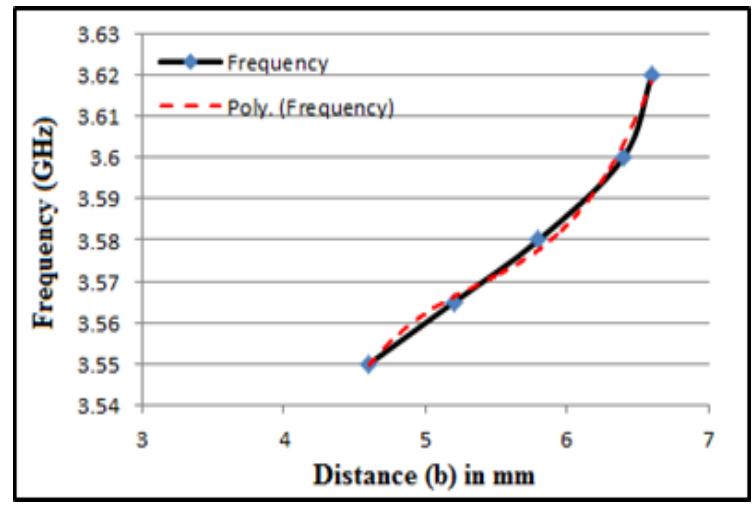

(b)

Figure 4. Effect of distance, (a) On axial ratio value, (b) On frequency of best AR value

\section{SIMULATION AND PRACTICAL RESULTS}

The proposed antenna is fabricated practically, as shown in Figure 5. The results for the input reflection coefficient (S11), radiation pattern, axial ratio, realize gain, and the input impedance is presented in this section. The antenna is simulated using CST environment and then measured is done using VAN from Vector-star Company. Furthermore, special glue material used to make a stacked substrate to increase (h) [25]. Good agreement is achieved between simulated and measured results.
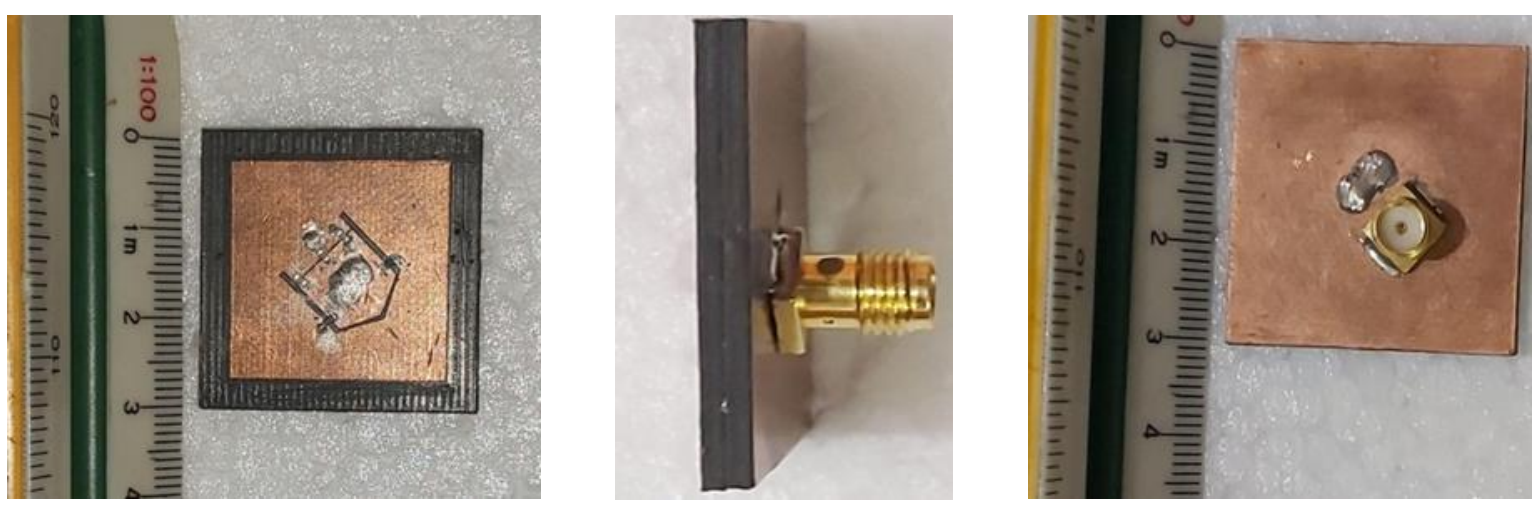

Figure 5. Photograph of the proposed antenna after fabrication

\subsection{Input reflection coefficient}

Figure 6 shows simulated and measured input-reflection coefficients for RHCP and LHCP senses corresponding to the two combination states of diodes operation. It is clear that the designed antenna has similar behavior in both RHCP and LHCP in terms of input reflection coefficient $\left(\mathrm{S}_{11}\right)$ values and impedance bandwidths in the two results. This is due to high symmetry in the proposed structure with respect to 
the diagonal line and feed point. However, the simulated impedance bandwidth for both polarization is $(6.4) \%$ in the frequency range of $(3.5$ to 3.7318$) \mathrm{GHz}$ with a resonant frequency of $3.6 \mathrm{GHz}$. While in measured results, the obtained bandwidth is about (5.9\%) starting from (3.5489 to 3.7654) GHz with resonant frequency at $3.6 \mathrm{GHz}$. In both simulated and measured curves, bandwidth covers the required resonant frequency at $3.6 \mathrm{GHz}$ with acceptable impedance matching and bandwidth. While the appeared difference in response may come from different error sources like substrate gluing process, lumped element integration, and fabrication tolerance.

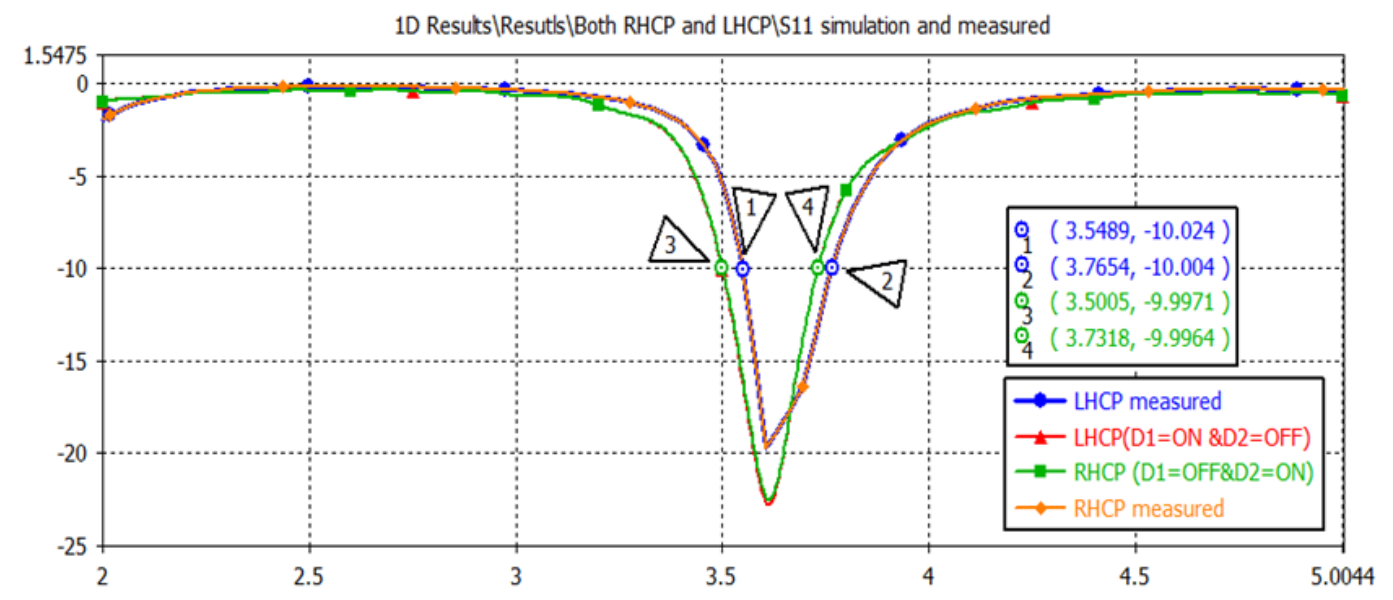

Figure 6. Input-reflection coefficient for LHCP and RHCP corresponding to D1 and D2 switches states

\subsection{Radiation pattern, axial ratio, gain}

Figure 7 shows the axial ratio (AR) at the broadside of the antenna as a function of frequency. For both $\mathrm{CP}$ senses, the minimum simulated value of the obtained $\mathrm{AR}$ is $(0.2 \mathrm{~dB})$ at the resonant frequency (3.6GHz) with stable CP bandwidth of (2.2\%) starting from (3.56 to 3.64) GHz. Due to lack of equipment, Vector Network Analyser (VNA) is used to predict CP performance of antenna practically. As shown in Figure 8 for the blue curve, the first mode is excited around $(3.74 \mathrm{GHz})$ and the second mode at $(3.57 \mathrm{GHz})$. Therefore, the axial ratio frequency will be at $(3.65 \mathrm{GHz})$. It is clear that there is an acceptable shift in the frequency between measured and simulated results. In fact, that shift may result from different sources, as mentioned above.

Figure 9 presents the simulation of far-field radiation patterns for the two polarization senses (RHCP and LHCP). Patten characteristics are simulated in the principal planes at 3.6GHz. In all cases, the minimum difference between the co-polarization level and the cross-polarization level is better than $(-25 \mathrm{~dB})$. Furthermore, it can be observed from the figure that all patterns are symmetrical about the broadside direction ( $+Z$ direction). In fact, the careful design contributes significantly to getting the above results.

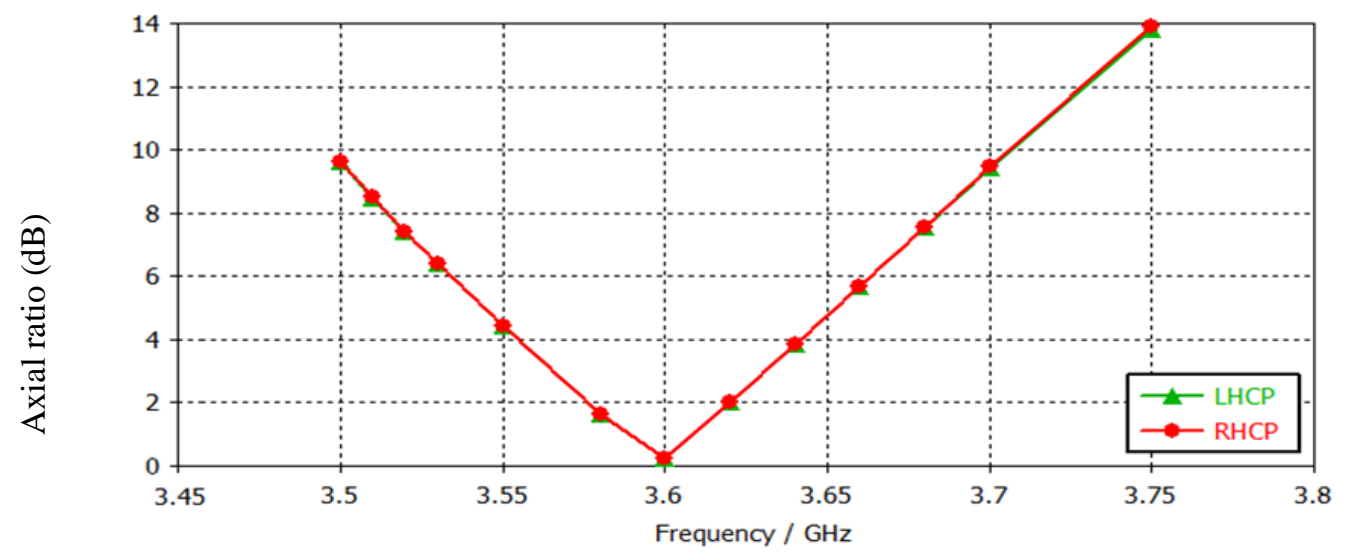

Figure 7. Simulated axial ratio vs frequency for both RHCP and LHCP modes 


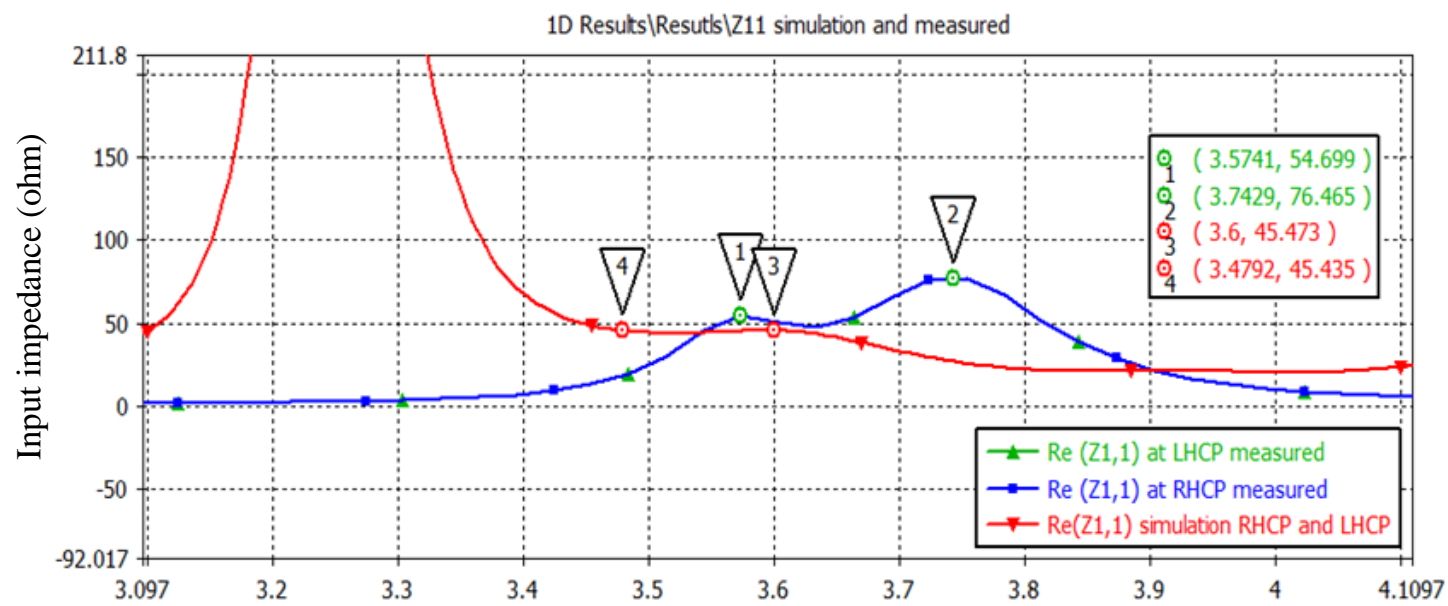

Figure 8. Measured axial ratio with respect to frequency based on measured input impedance of RHCP and LHCP

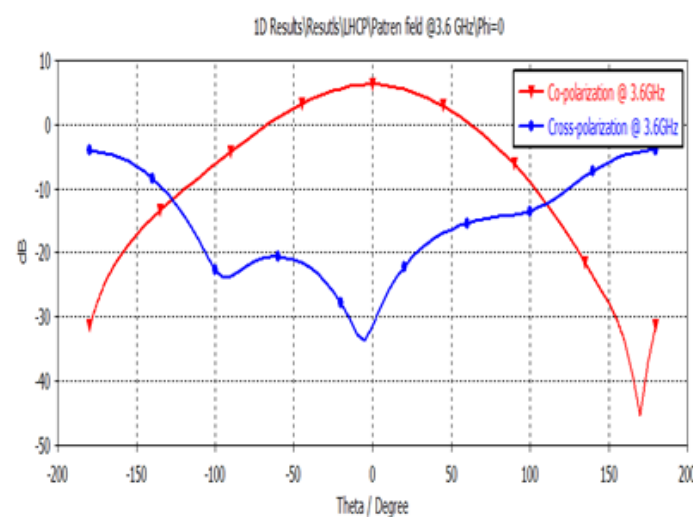

(a)

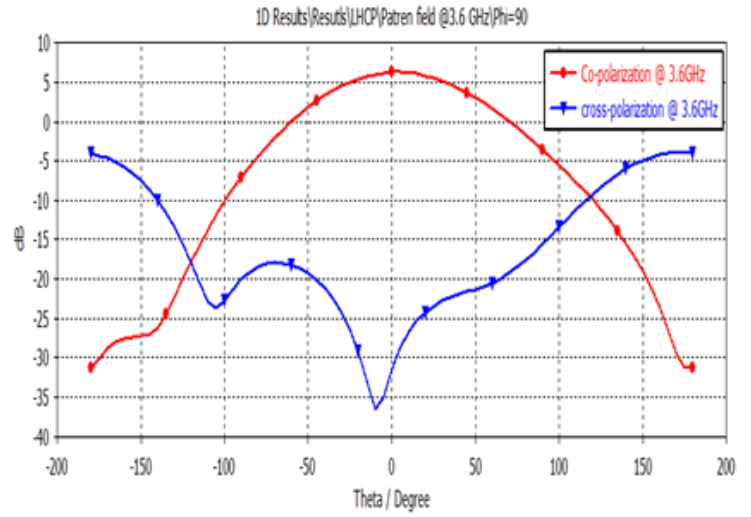

(c)

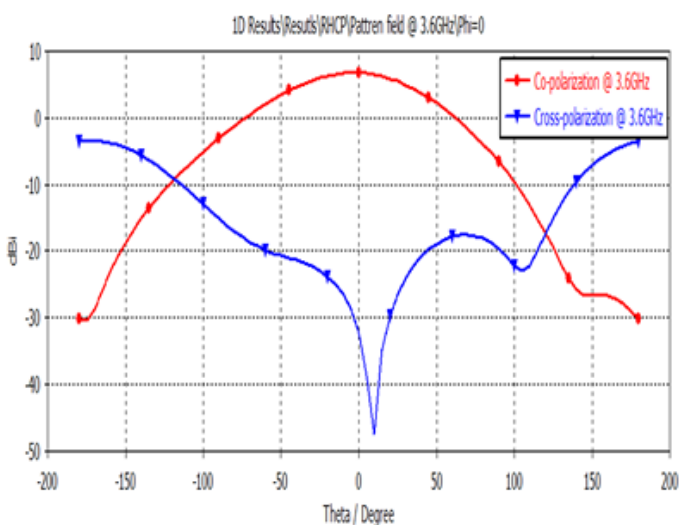

(b)

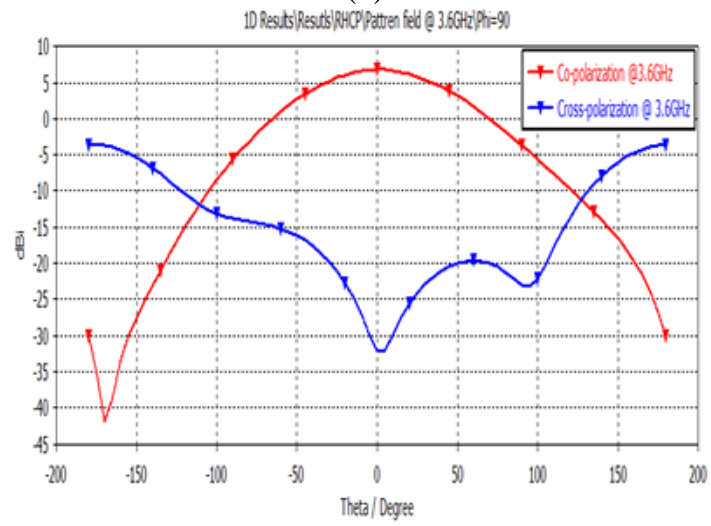

(d)

Figure 9. Results for radiation pattern for 3.6GHz, (a) LHCP in Z-X plane, (b) RHCP in Z-X plane, (c) LHCP in Z-Y plane, (d) RHCP in Z-y plane

Besides, the designed antenna delivered acceptable and approximately equal gains for both CP states, as in Figure 10. The maximum obtained value in the simulation was $(6.34 \mathrm{~dB})$. In Figure 11, the axial ratio vs. theta angle is simulated at the resonance frequency. It is clear that the antenna maintains a wider $\mathrm{AR}$ beamwidth of 120 degrees $\left(-60^{\circ} \leq A R \leq 60^{\circ}\right)$ centered in broadside direction in both principle planes $\left(\phi=0^{\circ}\right.$ and $\left.\phi=90^{\circ}\right)$. 


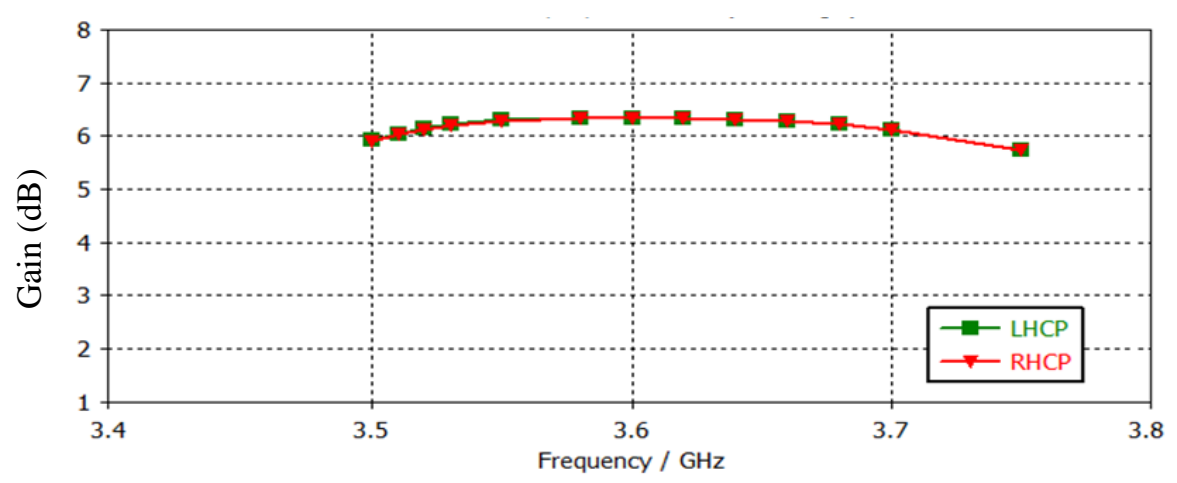

Figure 10. Realized gain of the designed antenna

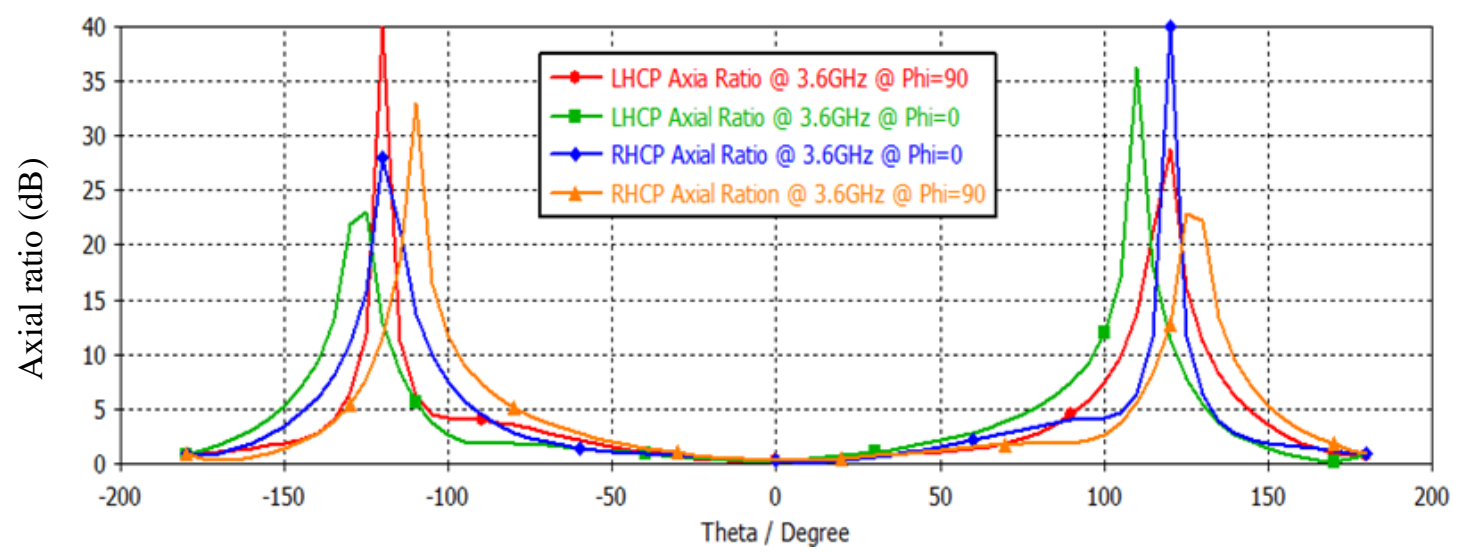

Figure 11. Simulated axial ratio vs. theta for both RHCP and LHCP modes in the principle planes

\section{COMPARISON WITH REPORTED ANTENNAS}

In Table 2, the designed antenna is compared with some previously published works. It is obvious that the proposed antenna has a smaller size with good CP performances at the $3.6 \mathrm{GHz}$ resonant frequency. Furthermore, bias tee is used in order to reduce biasing circuit complexity.

Table 2. Comparison between the designed and reported PRA

\begin{tabular}{cccccc}
\hline Reference & Size mm2 & Frequency $(\mathrm{GHz})$ & AR $(\mathrm{dB})$ & Gain $(\mathrm{dBi})$ & Notes \\
\hline$[6]$ & $40 * 40$ & 5.9 & 1 & 6.3 & Ideal switch \\
{$[8]$} & $34 * 34 * 3.2$ & 3.4 & 0.8 & 3.5 & Real diode \\
{$[10]$} & $40 * 40$ & 4.64 & ---- & ---- & Ideal switch \\
{$[11]$} & $55 * 55 * 1.6$ & 2.45 & 1 & 5 & Real diode \\
{$[12]$} & $\pi *(100)^{2}$ & 2.4 & 0.5 & 8 & Ideal switch \\
This work & $31 * 31 * 3.15$ & 3.6 & 0.2 & 6.34 & Real switch \\
\hline
\end{tabular}

\section{CONCLUSIONS}

This paper presents the design and simulation of a novel polarization reconfigurable square patch antenna. In this work, a new technique to obtain CP reconfigurable antenna is proposed. It combines among polygon U-slot, oriented switchable slots, and shorting post. Basically, the slot is divided into two switchable slots in vertical or horizontal direction depends on diode states. Due to high symmetry in design, good CP performance is achieved. On the other hand, shorting pins gives the ability to shift AR bandwidth over approximately entire impedance bandwidth leading to high flexibility in use. As a result, the simulated impedance bandwidth extends from (3.5 to 3.7318$) \mathrm{GHz}$ with resonant frequency at (3.6GHz). While an axial ratio bandwidth of $(2.2 \%)$ with the best value of $(0.2 \mathrm{~dB})$ at $(3.6 \mathrm{GHz})$ was achieved. Furthermore, the antenna has a compact size and good CP performance for both RHCP and LHCP. The designed antenna may be highly candidate to use in the mid-band frequency of $5 \mathrm{G}$ applications. 


\section{ACKNOWLEDGMENTS}

The authors would like to thank Mustansiriyah University (www.uomustansiriyah.edu.iq)/ Baghdad-Iraq for its support in the present work.

\section{REFERENCES}

[1] B. Babakhani and S. Sharma, "Wideband frequency tunable concentric circular microstrip patch antenna with simultaneous polarization reconfiguration," IEEE Antennas and propagation Magazine, vol. 57, no. 2, pp. 203-216, 2015.

[2] A. I. Al-Muttairi and M. J. Farhan, "Frequency reconfigurable Monopole antenna with harmonic Suppression for IoT applications," TELKOMNIKA Telecommunication Computing Electronic and Control, vol. 18, no. 1, pp. 10-18, 2020.

[3] N. O. Parchin, et al., "Recent developments of reconfigurable antennas for current and future wireless communication systems," Electronics, vol. 8, no. 2, p. 128, 2019.

[4] A. Bharathi, et al., "Reconfigurable corner truncated square microstrip patch antennas for wireless communication applications," IETE Journal of Research, vol. 66, no. 2, pp. 242-255, 2018.

[5] Y. B. Chen, et al., "A reconfigurable microstrip antenna with switchable polarization," Journal of Electromagnetic Waves and Applications, vol. 20, no. 10, pp. 1391-1398, 2006.

[6] P. Qin, et al., "Polarization reconfigurable U-slot patch antenna," IEEE Transactions on Antennas and Propagation, vol. 58, no. 10, pp. 3383-3388, 2010.

[7] B. Anantha, et al., "A novel single feed frequency and polarization reconfigurable microstrip patch antenna," $A E U$ International Journal of Electronics and Communications, vol. 72, pp. 8-16, 2017.

[8] Y. I. A. Al-Yasir, et al., "A new polarization-reconfigurable antenna for 5G applications. Electronics," Electronics, vol. 7, no. 11, pp. 293-301, 2018.

[9] Y. I. Abdulraheem, et al., "Design of frequency reconfigurable multiband compact antenna using two PIN diodes for WLAN/WiMAX applications," IET Microwaves, Antennas \& Propagation, vol. 11, no. 8, pp. 1098-1105, 2017.

[10] F. Yang and Y. R. Samii, "A reconfigurable patch antenna using switchable slots for circular polarization diversity," IEEE Microwave and Wireless Components Letters, vol. 12, no. 3, pp. 96-98, 2002.

[11] D. S. Rao, et al., "G-shaped polarization reconfigurable monopole antenna for WLAN applications," Journal of Advanced Research in Dynamical and Control Systems, vol. 9, pp. 2050-2058, 2017.

[12] K. M. Mak, et al., "Polarization reconfigurable circular patch antenna with a C- shaped," IEEE Transactions on Antennas and Propagation, vol. 65, no. 3, pp. 1388-1392, 2017.

[13] M. Fakharian, et al., "Reconfigurable multiband extended U-slot antenna with switchable polarization for wireless applications," IEEE Antennas and Propagation Magazine, vol. 57, no. 2, pp. 194-202, 2015.

[14] Y. E. Gholb, et al., "Wide-band circular antenna for 5G applications," Proceedings of $4^{\text {th }}$ International Conference on Optimization and Applications (ICOA), pp. 1-4, 2018.

[15] S. F. Jilani, et al., "Millimeter-wave frequency reconfigurable T-shaped antenna for 5G networks," Proceedings of $11^{\text {th }}$ International Conference on Wireless and Mobile Computing, Networking and Communications (WiMob), pp. 100-102, 2015.

[16] Y. Rahayu and M. I. Hidayat, "Design of 28/38 GHz Dual-Band Triangular-Shaped Slot Microstrip Antenna Array for 5G Applications," Proceedings of $2^{\text {nd }}$ International Conference on Telematics and Future Generation Networks (TAFGEN), pp. 93-97, 2018.

[17] E. Al-Abbas, et al., "Polarization reconfigurable antenna for $5 \mathrm{G}$ cellular networks operating at millimeter waves," Proceedings of IEEE Asia Pacific Microwave Conference (APMC), pp. 772-774, 2017.

[18] A. Panahi, et al., "A simple polarization reconfigurable printed monopole antenna," IEEE Transactions on Antennas and Propagation, vol. 63, no. 11, pp. 5129-5134, 2015.

[19] A. K. Jassim and R. H. Thaher, "Enhancement gain of broadband elliptical microstrip patch array antenna with mutual coupling for wireless communication," Indonesian Journal of Electrical Engineering and Computer Science, vol. 13, no. 1, pp. 217-225, 2019.

[20] DSM8100-000: Mesa Beam-Lead PIN Diode datasheet.

[21] R. B. Waterhouse, "Microstrip patch antennas: a designer's guide," Springer Science \& Business Media, 2013.

[22] G. Kumar and K. P. Ray, "Broadband microstrip antennas," Artech house, 2002.

[23] M. A. Rahman, et al., "A Polarization Reconfigurable Microstrip Antenna Employing Dual-Perturbation Technique," Progress in Electromagnetics Research M, vol. 69, pp. 197-206, 2018.

[24] W. L. Langston and D. R. Jackson, "Impedance, axial-ratio, and receive-power bandwidths of microstrip antennas," IEEE transactions on antennas and propagation, vol. 52, no. 10, pp. 2769-2774, 2004.

[25] Crystalbond ${ }^{\mathrm{TM}}$ Adhesives technical datasheet. 


\section{BIOGRAPHIES OF AUTHORS}

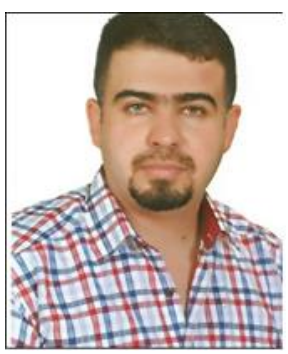

Alaa Imran was born in Tekrit-Iraq. He received the B.E. degree in electrical engineering from Babylon in 2005 and M.sc degree in electronics and communications engineering from the same university in 2013. He is working as lecturer in Information Technology college in Babylon University from January 2013. He is currently working his PhD degree at electrical engineering department in college of engineering at Mustansiriyah University in Bagdad. He has two patents and several researches published in high score journals. His research interests include IoT, antennas design, ,reconfigurable antenna design , and automation, etc.

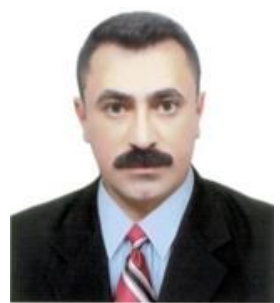

Assit. Prof. Dr. Malik Jasim Farhan Al-Khalidi received his B.E. Degree in Electrical engineering from the college of Engineering/ Mustansiriyah University in 1997. Then he received M.sc degree in Electronic and Communication engineering form the same university in 2000. In 2015, he got Ph.D. Degree in Electrical Engineering (Electronic and Communication) from the College of Engineering- Basrah University. He is currently the head of electrical engineering department / College of Engineering / Mustansiriya University since 7/10/2018 until now .Furthermore, he active researcher in antenna field. He interested in UWB antenna, design of MIMO and reconfigurable antennas. He published several articles in high score journals 